\title{
A Key Role for NF- $\kappa$ B Transcription Factor c-Rel in T-Lymphocyte-Differentiation and Effector Functions
}

\author{
Alexander Visekruna, ${ }^{1}$ Anton Volkov, ${ }^{1}$ and Ulrich Steinhoff ${ }^{1,2}$ \\ ${ }^{1}$ Institute for Medical Microbiology and Hygiene, Philipps University of Marburg, Hans Meerwein Straße 2, 35032 Marburg, Germany \\ ${ }^{2}$ Department of Immunology, Max Planck Institute of Infection Biology, 10117 Berlin, Germany
}

Correspondence should be addressed to Alexander Visekruna, alexander.visekruna@staff.uni-marburg.de

Received 8 October 2011; Revised 13 December 2011; Accepted 31 December 2011

Academic Editor: Niels Olsen Saraiva Camara

Copyright ( 92012 Alexander Visekruna et al. This is an open access article distributed under the Creative Commons Attribution License, which permits unrestricted use, distribution, and reproduction in any medium, provided the original work is properly cited.

\begin{abstract}
The transcription factors of the Rel/NF- $\kappa \mathrm{B}$ family function as key regulators of innate and adoptive immunity. Tightly and temporally controlled activation of NF- $\kappa \mathrm{B}$-signalling pathways ensures prevention of harmful immune cell dysregulation, whereas a loss of control leads to pathological conditions such as severe inflammation, autoimmune disease, and inflammation-associated oncogenesis. Five family members have been identified in mammals: RelA (p65), c-Rel, RelB, and the precursor proteins NF$\kappa \mathrm{B} 1(\mathrm{p} 105)$ and NF- $\kappa \mathrm{B} 2$ (p100), that are processed into p50 and p52, respectively. While RelA-containing dimers are present in most cell types, c-Rel complexes are predominately found in cells of hematopoietic origin. In T-cell lymphocytes, certain genes essential for immune function such as Il2 and Foxp3 are directly regulated by c-Rel. Additionally, c-Rel-dependent IL-12 and IL23 transcription by macrophages and dendritic cells is crucial for T-cell differentiation and effector functions. Accordingly, c-Rel expression in T cells and antigen-presenting cells (APCs) controls a delicate balance between tolerance and immunity. This review gives a selective overview on recent progress in understanding of diverse roles of c-Rel in regulating adaptive immunity.
\end{abstract}

\section{Introduction}

c-Rel is a member of the Rel/NF- $\kappa$ B family of eukaryotic transcription factors, which also includes the proteins RelA (p65), RelB, NF- $\kappa$ B1 (p105/p50), and NF- $\kappa$ B2 (p100/p52). $\mathrm{NF}-\kappa \mathrm{B}$ transcription factors can form various homo- and heterodimers possessing unique specificities in regulating target gene expression [1]. Despite some redundancy, functional studies on mice lacking one or more NF- $\kappa \mathrm{B}$ proteins revealed that distinct NF- $\kappa \mathrm{B}$ subunits play specific role in regulating T-cell development and effector functions [2-5]. NF- $\kappa \mathrm{B}$ complexes are held in the cytoplasm by interacting with a family of inhibitory proteins known as the $\mathrm{I} \kappa \mathrm{B}$ proteins. In general, binding of $\mathrm{I} \kappa \mathrm{B}$ proteins to NF- $\kappa \mathrm{B}$ dimers masks the nuclear localization signals of NF- $\kappa \mathrm{B}$ proteins and inhibits both, nuclear import of NF- $\kappa \mathrm{B}$ complexes as well as binding to their specific DNA binding site $(\kappa \mathrm{B}$ site) [6]. Activation of NF- $\kappa$ B complexes in T lymphocytes requires $\mathrm{T}$-cell receptor (TCR) stimulation, which provides a signal for phosphorylation and degradation of $\mathrm{I} \kappa \mathrm{B}$ proteins via the ubiquitin-proteasome system in order to initiate nuclear translocation and DNA binding of active NF- $\kappa \mathrm{B}$ dimers [7]. In the past decade, several studies have been conducted to identify genes that are directly regulated by the transcription factor c-Rel [8-12]. Despite extensive research, not all c-Rel-controlled genes have been identified yet. Most information about the role of c-Rel in T lymphocytes has come from in vivo analyses of c-Rel deficient mice suggesting an important function for this protein in regulating $\mathrm{T}$ cell development, differentiation, and effector function in thymus and peripheral lymphoid tissues. This review attempts to highlight various nonredundant physiological functions of c-Rel, particularly with regard to regulation of T-cellmediated immunity.

\section{2. c-Rel-Signalling Pathway in T Lymphocytes}

Three main NF- $\kappa \mathrm{B}$ activating pathways exist in mammalian cells [13]. The so-called canonical NF- $\kappa$ B pathway by which cytokines and other various signals initiate activation of 
RelA/p50 and c-Rel/p50 heterodimers has been investigated in greatest detail. A central component in NF- $\kappa \mathrm{B}$ regulation is a serine-specific I $\kappa B$ kinase (IKK), a complex composed of three subunits: IKK $\alpha$ (IKK1), IKK $\beta$ (IKK2), and IKK $\gamma$ (NEMO). In $\mathrm{T}$ lymphocytes, the canonical pathway is triggered by TCR and CD28 engagement resulting in activation of IKK $\alpha / \mathrm{IKK} \beta / \mathrm{IKK} \gamma$ complex. Following stimulation, activation of IKK results in phosphorylation of I $\kappa$ Bs on specific serine residues, recruitment of the $\mathrm{SCF}^{\beta-\operatorname{TrCP}}$ ubiquitin ligase complex, rapid polyubiquitination, and subsequent degradation of $\mathrm{I} \kappa \mathrm{B}$ inhibitory proteins by the $26 \mathrm{~S}$ proteasome [14]. I $\kappa \mathrm{B} \alpha$ is phosphorylated by IKK $\beta$ on two N-terminal serine residues, Ser32 and Ser36, which creates a binding site for the receptor subunit $(\beta-\operatorname{TrCP})$ of specific ubiquitin E3 ligase SCF. Once liberated from I $\kappa$ B molecules, p65/50 and c-Rel/p50 dimers participate in the transcriptional regulation of distinct genes involved in adaptive immunity functions. In contrast, the alternative NF- $\kappa \mathrm{B}$ activation pathway is induced by a subset of TNFR family members (e.g., LT $\beta$ R and BAFFR) involving NIK and IKK $\alpha$-mediated p100 processing and generation of transcriptionally active p52/RelB heterodimers $[15,16]$ (Figure 1). The major function of this pathway is related to the development and organization of secondary lymphoid organs (downstream of LT $\beta$ R) and homeostasis of B cells (downstream of BAFFR) $[6,17]$. Although T cells express a number of costimulatory TNFR family members such as OX40, CD30, and GITR that are assumed to induce processing of p100 via activation of NIK and IKK $\alpha$ homodimers $[18,19]$, it remains largely unclear how the alternative NF- $\kappa$ B pathway exactly regulates T-cell differentiation, effector functions, and memory responses. The third NF- $\kappa$ B pathway, also called p105 pathway, is initiated by IKK $\beta$ through phosphorylation of p105 precursor protein at Ser927 and Ser932. It uses the same IKK complex as the canonical pathway and its activation lead to complete degradation of the p105 molecule and release of docked molecules $[14,20,21]$.

Since the discovery of NF- $\kappa$ B proteins 25 years ago, there have been many questions with respect to the selectivity and diversity of NF- $\kappa$ B functions. Novel studies have begun to reveal how the complex networks of positive and negative regulatory signals and crosstalk between activating pathways shape the NF- $\kappa \mathrm{B}$ response in a cell-typedependent and stimulus-specific way [17, 22-24]. In naïve $\mathrm{T}$ cells, TCR stimulation and subsequent IKK $\beta$-dependent phosphorylation of $\mathrm{I} \kappa \mathrm{B} \alpha$ lead to the nuclear translocation of active NF- $\kappa \mathrm{B}$ dimers. The protein kinase $\mathrm{C}$ isozyme PKC$\theta$ is a central molecule for recruiting additional factors required for IKK-mediated NF- $\kappa$ B activation in T cells. TCRmediated activation of $\mathrm{p} 65 / \mathrm{p} 50$ and $\mathrm{c}-\mathrm{Rel} / \mathrm{p} 50$ dimers in $\mathrm{T}$ cells includes activation of kinases of the Src and the Syk families. Furthermore, CD28 and TCR costimulation facilitates phosphorylation of CARMA1 and its recruitment into signalling complex with Bcl10 and MALT1 (CBM complex, Figure 1). Although not completely elucidated, mechanisms such as linear ubiquitination of NEMO and phosphorylation of IKK $\beta$ (probably by TAK1) lead to the activation of the IKK complex and phosphorylation of I $\kappa$ Bs
[16]. Cellular localization of NF- $\kappa \mathrm{B}$ proteins is controlled by three $\mathrm{I} \kappa \mathrm{B}$ isoforms: $\mathrm{I} \kappa \mathrm{B} \alpha, \mathrm{I} \kappa \mathrm{B} \beta$ and $\mathrm{I} \kappa \mathrm{B} \varepsilon$. Interestingly, the rate of degradation and resynthesis of each $\mathrm{I} \kappa \mathrm{B}$ isoform may vary in cell-specific way [25]. Whereas $\mathrm{I} \kappa \mathrm{B} \alpha$ mediates rapid NF- $\kappa \mathrm{B}$ activation and strong negative feedback loop regulation, $\mathrm{I} \kappa \mathrm{B} \beta$ and $\mathrm{I} \kappa \mathrm{B} \varepsilon$ allow a relatively stable NF$\kappa \mathrm{B}$ response by responding more slowly and acting to dampen oscillatory NF- $\kappa \mathrm{B}$ activation profile [25-27]. An important question is how the closely related RelA and c-Rel proteins can operate distinctly in $\mathrm{T}$ lymphocytes and whether the inhibitory I $\kappa$ Bs play a central role in these processes. Recent studies suggest that triggering the TCR/CD3 complex results in rapid translocation of active p65-containing dimers into the nucleus and slower activation of c-Rel complexes. As consequence, $\mathrm{c}$-Rel-dependent gene transcription in $\mathrm{T}$ cells is slower as compared to p65-mediated responses. In unstimulated $\mathrm{T}$ cells, c-Rel is primarily associated with $\mathrm{I} \kappa \mathrm{B} \beta$, and the proportion of $\mathrm{c}-\mathrm{Rel}$ bound to $\mathrm{I} \kappa \mathrm{B} \alpha$ can be substantially increased after activation of cells with TNF$\alpha$ and IL- $1 \beta[28,29]$. In particular, $\mathrm{I} \kappa \mathrm{B} \alpha$ is degraded more rapidly than $\mathrm{I} \kappa \mathrm{B} \beta$ and $\mathrm{I} \kappa \mathrm{B} \varepsilon$. Taken together, in naïve $\mathrm{T}$ cells, two members of the classical NF- $\kappa \mathrm{B}$ activating pathway, p65 and c-Rel, seem to be differentially regulated by forming distinct complexes with I $\kappa$ Bs. $c$-Rel dimers cannot be easily activated as c-Rel is mainly complexed to $\mathrm{I} \kappa \mathrm{B} \beta$. Costimulatory signals transmitted by CD80/86/CD28 and the presence of proinflammatory cytokines secreted by APCs increase $\mathrm{I} \kappa \mathrm{B} \beta$ degradation and c-Rel is consequently shifted to $\mathrm{I} \kappa \mathrm{B} \alpha$-associated complexes [29].

Remarkably, turnover of c-Rel itself seems to be regulated by the ubiquitin-proteasome pathway adding another level of the complexity to its regulation [30]. A novel study has described that the E3 ubiquitin ligase Peli1 mediates polyubiquitination of c-Rel and subsequent degradation of this protein by the $26 \mathrm{~S}$ proteasome. This prevents aberrant accumulation of c-Rel during T-cell activation. Interestingly, Peli1 deficiency in mice results in nuclear accumulation of cRel, T-cell hyperactivation, and spontaneous development of autoimmunity associated with multiorgan inflammation and production of autoantibodies [31]. This finding emphasizes that regulation of $\mathrm{c}-$ Rel expression in $\mathrm{T}$ cells might play an important role in the maintenance of peripheral T-cell tolerance.

\section{Cell-Autonomous Role of c-Rel in T-Lymphocyte Differentiation}

The differentiation of the $\mathrm{CD}^{+} \mathrm{T}$-cell lineage into $\mathrm{T}$ effector cells is a crucial prerequisite for a successful host immune defense against pathogens. Functional specialization is coordinated by a complex genetic network, initiated and terminated in a time-dependent manner. Several studies have attempted to identify transcriptional signatures and master transcription factors driving the differentiation of individual T-cell subsets. Recently, a discovery of huge range of the functional plasticity and heterogeneity of T-cells has drawn much attention [32, 33]. As several subpopulations have only been examined in vitro, it is still unclear if they 


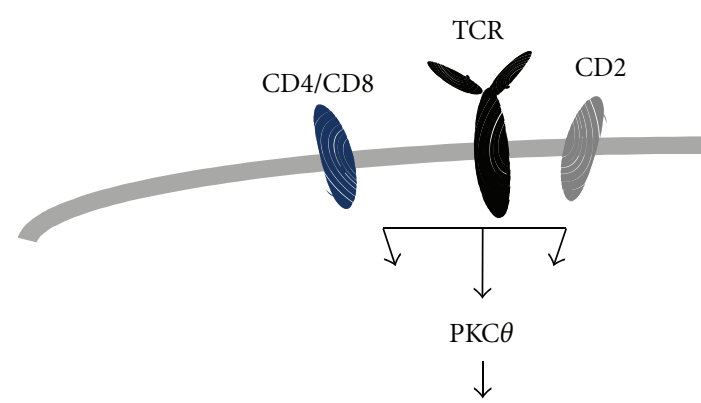

CARMA1/Bcl10/MALT1

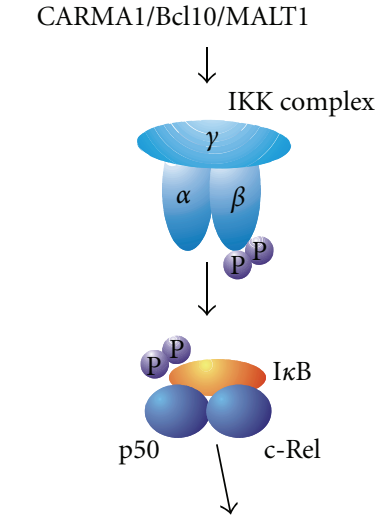

NFR family members

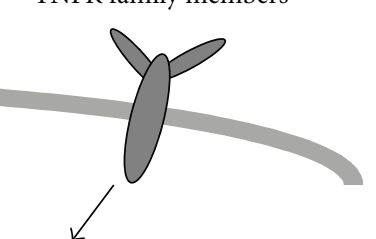

$\stackrel{\text { NIK }}{\downarrow}$

$\mathrm{IKK} \alpha / \mathrm{IKK} \alpha$

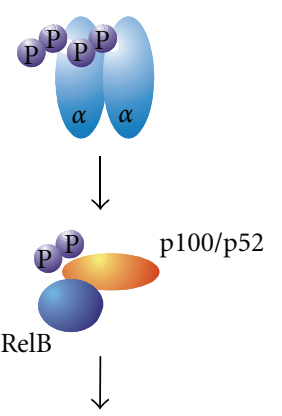

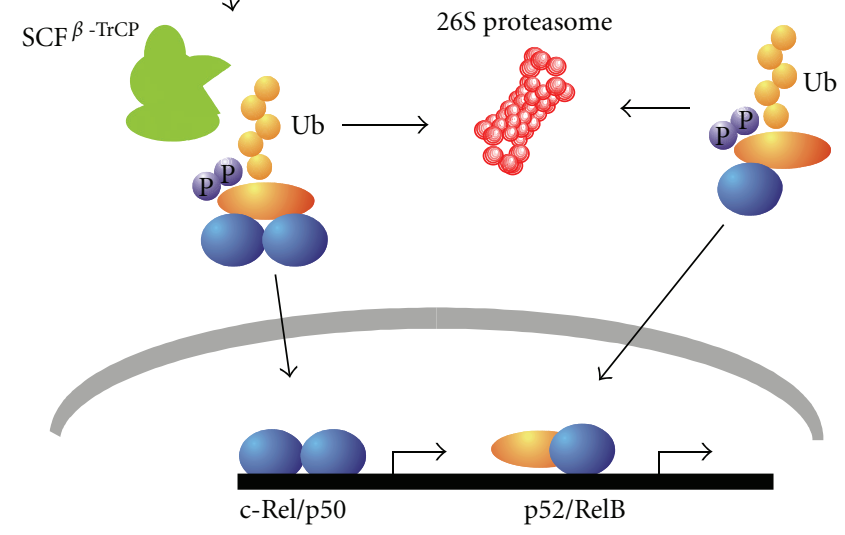

FIGURE 1: Canonical and alternative NF- $\kappa \mathrm{B}$ activation pathways in $\mathrm{T}$ cells. Several signals are required for the activation of the canonical $\mathrm{NF}-\kappa \mathrm{B}$-signalling pathway. The inhibitory $\mathrm{I} \kappa \mathrm{B}$ proteins typically bind to dimers of the NF- $\kappa \mathrm{B}$ family such as p65/p50 (not shown in the figure) and c-Rel/p50 to generate inactive complexes that are sequestered in the cytosol. PKC $\theta$ is a central molecule for TCR-mediated NF$\kappa \mathrm{B}$ activation. Phosphorylation of CARMA by PKC $\theta$ results in formation of stable CARMA/Bcl10/MALT1 complex and activation of IKK. Activated IKK $\beta$ kinase mediates phosphorylation of $\mathrm{I} \kappa \mathrm{B}$ molecules and recruitment of $\mathrm{SCF}^{\beta \text {-TrCP }}$ ubiquitin ligase. Activation of alternative NF- $\kappa \mathrm{B}$ pathway is triggered by a subset of TNFR family members and is mediated by NIK and IKK $\alpha$ that phosphorylates p100. The ubiquitinproteasome pathway is involved in activation of NF- $\kappa$ B via specific degradation of $\mathrm{I} \kappa \mathrm{Bs}$ and processing of p100 to produce p52.

should be considered as distinct $\mathrm{T}$ cell subsets or whether expression of characteristic molecules is just an adaptation of already known and well-described Th1, Th2, and Th17 cells to certain microenvironment. This review aims to discuss the data that will allow us to understand how cRel influences the development and effector functions of most important T-cell subsets. Th1 and Th2 cells have distinct immunological functions by producing their key cytokines IFN- $\gamma$ and IL-4, respectively. Recently, IL-17producing cells that express transcription factors IRF-4 and ROR $\gamma$ t, named Th17 cells, have been described to develop via a unique lineage, independently of the Th1 and Th2 master transcription factors T-bet and GATA-3 [34-37]. Another population of $\mathrm{CD}^{+} \mathrm{T}$ cells, so-called follicular helper $\mathrm{T}$ cells $\left(\mathrm{T}_{\mathrm{FH}}\right)$, preferentially reside in germinal centres where they help B cells to generate high-affine antibodies [38, 39]. Finally, regulatory $\mathrm{T}$ (Treg) cells are characterized by their expression of transcription factor Foxp3 and are essential for tolerance and prevention of autoimmunity $[40,41]$.

The transcription factor c-Rel has emerged to be an important molecule that can mediate proliferation, differentiation, and cytokine production of $\mathrm{T}$ cells. However, the extent and impact of the described defects in c-Reldeficient T-cells vary considerably. Experiments with c-Reldeficient mice have revealed that this protein is crucial for optimal IL-2 production and expression of IL-2R $\alpha$ 
(CD25) in T cells $[42,43]$. Normally, immature T cells are unable to produce IL-2. However, once dendritic cells (DCs) encounter danger signals at the site of infection and get fully maturated, differentiation, of naïve $\mathrm{CD}^{+} \mathrm{T}$ cells is driven effectively through antigen recognition, cytokine milieu, and costimulation by CD80 and CD86. In response to antigens, T cells start producing IL-2 and IL-2/IL2-R-signalling becomes crucial for their activation and expansion. In light of the finding that $\mathrm{c}$-Rel complexes are mainly bound to $\mathrm{I} \kappa \mathrm{B} \beta$ and that stimulation via CD28 leads to degradation of $\mathrm{I} \kappa \mathrm{B} \beta$ and activation of c-Rel signalling pathway, it is evident why cRel-deficient $\mathrm{T}$ cells cannot respond appropriately to T-cell activation signals. With regard to activated naïve $\mathrm{T}$ cells, c-Rel signalling (acting downstream of TCR and CD28) may also be essential for secretion of other IL-2-dependent cytokines. IL-2 is known to be required for optimal IL-4 and IFN- $\gamma$ expression by T-helper cells and for expression of granzyme and perforin by cytotoxic T lymphocytes (CTL) $[44,45]$. Since c-Rel, AP-1, and NFAT act in concert to regulate IL-2 expression and T-cell proliferation, IL-2 secretion is reduced but not completely abrogated in c-Rel-deficient $\mathrm{T}$ cells. Thus, some defects in Th differentiation observed under in vitro polarizing conditions in the absence of cRel may indirectly result from decreased T-cell proliferation. Interestingly, in mature effector $\mathrm{T}$ cells that differ from naïve ones by producing cytokines more rapidly after TCR stimulation, IL-2 and IFN- $\gamma$ gene expression seems to occur independently of c-Rel-mediated signal transduction [29].

It is likely that regulatory functions of c-Rel on target gene promotors are accomplished by heterodimerization with p50 or by forming $\mathrm{c}-\mathrm{Rel} / \mathrm{c}-\mathrm{Rel}$ homodimers. There is also evidence that $\mathrm{c}-\mathrm{Rel} / \mathrm{p} 50$ dimers cooperate with other NF- $\kappa$ B family members. For example, c-Rel and p65 complexes bind together to IL-2R $\alpha$ promoter and even cooperate with other transcription factors such as SRF to increase expression of IL-2R $\alpha$ gene [46]. Recently, a c-Rel binding site was identified in proximal promoter of Il21 gene implicating an important role for c-Rel in development of IL21-dependent T and B subsets [47]. IL-21 has been reported to be essential for both $\mathrm{T}_{\mathrm{FH}}$ development and regulation of B-cell function [38, 48-51]. Accordingly, the frequencies of $\mathrm{T}_{\mathrm{FH}}$ cells and germinal centre (GC) B cells were significantly reduced in c-Rel-deficient mice immunized with $\mathrm{MOG}_{35-55}$ [47]. We have also found reduced IL-21 production and GC formation in Peyer's patches of c-Rel-deficient mice (A. Visekruna, unpublished data). However, our recent unpublished results show that, at least in response to IL6 stimulation, there was no significant difference between WT- and c-Rel-deficient $\mathrm{CD}^{+}{ }^{+} \mathrm{T}$ cells with respect to IL21 production. This suggests that c-Rel might be involved in IL-6-independent signal transduction pathways leading to induction of IL-21 expression. Although c-Rel binds to the promoter of the Il21 gene, many other transcriptional activators such as STAT-3, IRF-4, and NFATc2 seem to be more important for optimal Il21 gene expression [52, 53].

More recently, c-Rel has been shown to control the differentiation of Treg cells in the thymus by promoting formation of so-called Foxp3-specific "enhanceosome [sic]" containing p65, Smad3, NFATc2, and CREB [54-58]. It has also become evident that c-Rel protein and RNA expression are specifically upregulated in $\mathrm{CD} 4{ }^{+} \mathrm{CD} 25^{+}$thymocytes as compared to other $\mathrm{T}$-cell populations in the thymus indicating the importance of this factor for development and maintenance of emerging Treg population. Intriguingly, although c-Rel-deficient mice exhibit diminished Treg cell numbers, c-Rel appears to be dispensable for immune suppressive activity of Treg cells, as c-Rel-deficient Treg cells are able to inhibit T-cell proliferation in vitro and suppress development of T-cell-induced colitis [58]. Three highly conserved noncoding DNA sequences (CNSs) in the Foxp3 locus have been identified and named CNS1-3. In silico analysis has revealed that c-Rel complexes but not p65 complexes bind to CNS3 region of Foxp3 locus resembling the CD28 response element (CD28RE) in the Il2 locus, also known to be occupied by c-Rel homodimers [59]. Given the importance of Foxp3 expression in Treg differentiation and effector functions, an interesting consideration point is to better understand how intracellular signalling molecules and adapters are involved in NF- $\kappa \mathrm{B}$ activation in Treg population. Although engagement of TCR and IL-2 signalling is crucial for both thymic and peripheral development of Treg cells, the overall "quality" of peripheral signals may not mimic all facets of Treg development in thymus. While TCR signalling via c-Rel provides an instructive signal to open the Foxp3 locus during thymic development, additional factors are probably involved in the generation of peripheral Treg (iTreg) cells. Very recently, we have demonstrated that, in the presence of TGF- $\beta$, the addition of exogenous IL- 2 is sufficient to drive iTreg differentiation and to upregulate Foxp3 expression in c-Rel-deficient naïve $\mathrm{CD} 4^{+} \mathrm{T}$ cells [60]. Further, our unpublished data suggest that in vivo treatment with immune complexes consisting of IL-2 and anti-IL-2 mAb (JES6-1) leads to a widespread increase in Treg cell frequencies not only in WT but also in c-Rel deficient mice. The paradoxical observation that frequencies of Treg cells increase substantially in c-Rel deficient mice implies that, at least in the periphery, control of the Foxp3 locus by cRel is not required for maintaining the homeostasis and expansion of Treg cells. Interestingly, thymic and peripheral $\mathrm{CD}^{+}{ }^{+}$Foxp $3^{+}$Treg cell frequencies are also significantly reduced in mice deficient in upstream components of cRel-activating pathway such as PKC- $\theta$, CARMA1, Bcl10, and MALT1 [56, 61-63]. It will be of interest to determine if iTreg cells generated from these mice induce Foxp3 after in vitro exposure to IL- 2 and TGF- $\beta$ similarly to c-Rel-deficient $\mathrm{T}$ cells. These findings collectively suggest that c-Rel has an important nonredundant function for Treg cells by inducing Foxp3 expression during thymic Treg cell development.

Additionally to its role in several $\mathrm{CD}^{+} \mathrm{T}$ subsets, $\mathrm{c}^{-}$ Rel might play an important role for $\mathrm{CD}^{+}$T-cell function. One mechanism in particular is regulation of IL-2 production as consumption of this cytokine has a crucial influence on various aspects of $\mathrm{CD}^{+} \mathrm{T}$-mediated immunity. Current experimental data indicate that the PKC- $\theta / \mathrm{c}$-Relsignalling axis is a crucial survival pathway in activated CD ${ }^{+}$ $\mathrm{T}$ lymphocytes. Interestingly, exogenous IL-2 can bypass survival and proliferative defects in PKC- $\theta$ - and c-Reldeficient $\mathrm{CD}^{+} \mathrm{T}$ cells [64]. Additionally, in the presence of 
exogenous IL2, c-Rel-deficient CTL have normal cytotoxicity in vitro. In vivo studies have shown normal capacity of c-Reldeficient $\mathrm{CD}^{+} \mathrm{T}$ cells to clear influenza infection [65]. Major contribution of c-Rel to functional CTL responses might comprise regulation of the inflammatory environment (e.g., regulation of cytokines produced by APC and $\mathrm{CD}^{+} \mathrm{T}$ cells) rather than playing substantial intrinsic role in cytotoxic $\mathrm{T}$ cells.

\section{Crucial Role of c-Rel in Regulating Inflammation and Immune Defense against Microbial Pathogens}

In vitro analyses of c-Rel-deficient cells have revealed selective requirement for c-Rel during IL-12 p40 induction in macrophages [66]. Similarly, p50/c-Rel dimers have been described to bind to the proximal promoter of IL-12 p35 and IL-23 p19 subunits in murine macrophages and DC [67-70]. Both proteins, IL-12 and IL-23, play a crucial role for the differentiation of $\mathrm{T}$ lymphocytes and immunity against pathogens. Importantly, maturation of DC is not affected in the absence of c-Rel, whereas the loss of this protein in APC compromises DC-mediated $\mathrm{CD} 4^{+}$T-cell activation [71]. Thus, c-Rel appears to be a crucial link between innate immune signals and primary $\mathrm{T}$-cell responses by substantially influencing a delicate balance between Th1, Th17, and Treg cells.

Complex in vivo functions of different NF- $\kappa \mathrm{B}$ family members following exposure to pathogens remain partially controversial. Infected mice devoid of specific NF- $\kappa$ B proteins display distinct phenotypes probably reflecting the ability of individual members to regulate expression of different sets of target genes associated with innate and adoptive immunity. One of the fundamental immunological challenges is to understand how the immune system can decide what type of immune responses to launch against different classes of pathogens. The capacity of Th1 and $\mathrm{Tc} 1$ responses to protect against intracellular pathogens is well known. For example, the control of infection with protozoan parasite Leishmania major has been attributed to IL-12-mediated differentiation and expansion of $\mathrm{CD} 4^{+}$ Th1 cells with subsequent IFN- $\gamma$ secretion, activation of infected macrophages, and NO-mediated killing of parasite. Two studies have shown that mice lacking c-Rel display a high susceptibility to $L$. major infection. The reduced levels of IL-12 p70 in DC as well as defective IFN- $\gamma$ secretion by $\mathrm{T}$ cells and NO production by macrophages in both L. major-infected MyD88 and c-Rel-deficient mice suggest that the high susceptibility of such animals is dependent on TLR-induced activation of c-Rel-signalling pathway with subsequent development of IL-12-mediated protective Th1 response against Leishmania parasites [72-74]. One might assume that this mechanism displays a general dependency of protective Th1 immunity on c-Rel, particularly involving regulation of IL-12 production by this transcription factor in APC. Although the failure of c-Rel deficient mice to control infection with another intracellular parasite Toxoplasma gondii was also associated with defective Th1 responses, in contrary to infection with $L$. major, this effect appears to be rather dependent on T-cell-intrinsic expression of cRel [75]. Thus, the evidence that c-Rel is essential for the production of IL-12 in response to LPS and Leishmania, but dispensable for IL-12 production in response to Toxoplasma, suggests that this transcription factor is associated with various complex aspects of regulation of innate and adaptive responses required to control infections [76].

There are emerging insights that c-Rel might play a key role in inflammatory diseases. Recent studies from several groups have shown that c-Rel is essential for the development of both colitis as well as experimental autoimmune encephalomyelitis (EAE). Impaired Th1 and Th17 development seems to occur in parallel with protection from EAE in c-Rel-deficient mice $[47,77,78]$. While potentially multiple roles of c-Rel in the inductive and effector stages of EAE are still partially elusive, its innate function in the control of proinflammatory responses during an intestinal inflammation is well known $[79,80]$. A defect in the intestinal epithelial barrier function is an important etiologic factor leading to development of inflammatory bowel disease (IBD) in humans. After encountering microbial agents, activation of c-Rel in DC leads to induction of IL-23 and IL-12 expression. IL-23 strongly enhances production of IL-17 by previously primed $\mathrm{CD} 4^{+} \mathrm{T}$ cells and probably by recently described innate lymphoid cells (ILCs) [81]. The regulation of IL- 23 by c-Rel within APC has a critical role in mediating chronic intestinal inflammation. A recent genetic study in humans and several studies in mice have uncovered IL-23 as a key factor in the pathogenesis of Crohn's disease [82-85]. The role of c-Rel and other NF- $\kappa \mathrm{B}$ family members can be regulated at many different levels. Two very recent studies have provided important clues to the underlying mechanisms of Th17-cell mediated diseases, showing that c-Rel is required for ROR $\gamma$ t expression in $\mathrm{T}$ cells $[78,86]$. Therefore, both c-Rel expressed by $\mathrm{CD}^{+} \mathrm{T}$ cells regulating directly the expression of a Th17 lineage-specific transcription factor ROR $\gamma \mathrm{t}$ as well as c-Rel expression by myeloid cells contribute to differentiation and maintenance of Th17 cells. Results obtained from mouse models and human specimens show that, besides c-Rel-mediated Th17 cell differentiation, IFN- $\gamma$-mediated induction of immunoproteasomes has an important role for activation of NF$\kappa \mathrm{B}$ and enhancement of chronic inflammation in the gut $[80,87,88]$. Collectively, induction of inflammation in the gut caused by imbalanced activation of DC expressing high level of c-Rel and immunoproteasomes contributes to IBD by augmenting proinflammatory Th1 and Th17 responses (Figure 2). Novel data have also indicated that, in addition to T cells, ILC might be important factors driving intestinal inflammation in mice and humans $[89,90]$. However, the role of NF- $\kappa$ B transcription factor c-Rel in regulating various effector functions of these cells has not been characterized yet.

\section{Conclusions and Future Directions}

In last 25 years, major steps forward have been made in understanding how NF- $\kappa \mathrm{B}$ regulates different aspects of the 


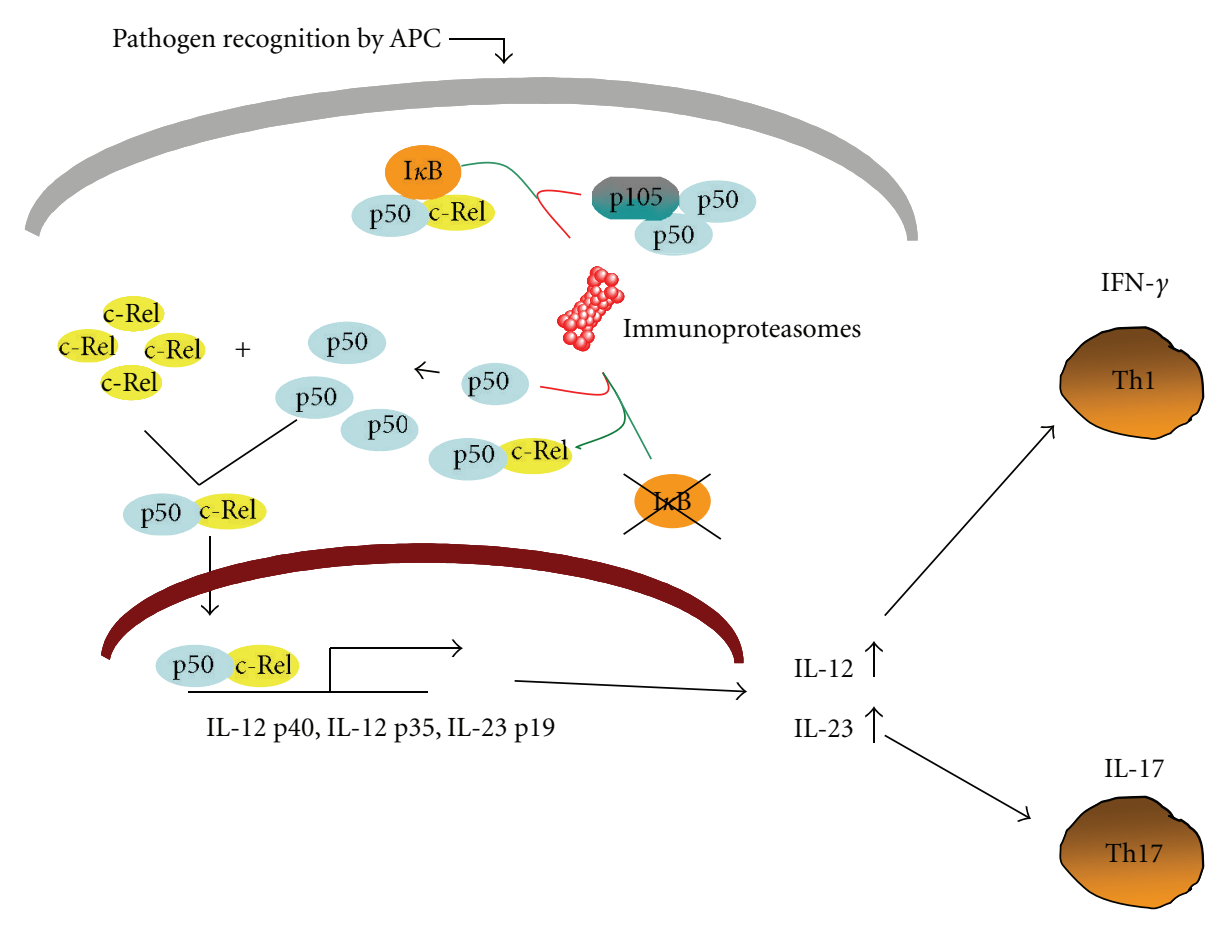

FIGURE 2: Induction of immunoproteasomes and c-Rel signalling in APC during intestinal inflammation. After disruption of intestinal barrier, the activation of DC by innate immunity triggers such as TLR ligands results in signalling cascade that induces expression of immunoproteasomes. The immunoproteasome is highly active form of proteasome that enhances activation of NF- $\kappa \mathrm{B}$ signalling. Additionally, stimulation of TLR releases c-Rel/p50 dimers from I $\kappa$ B to bind to the p40, p35, and p19 promoter. The synergy between immunoproteasomes and c-Rel leads to an increase of IL-12 and IL-23 secretion by APC contributing directly to T-cell-mediated immune responses and exacerbation of intestinal inflammation.

immune system. Several studies have begun to examine the role of specific NF- $\kappa$ B family members in regulating infections and chronic inflammatory disorders. c-Rel has emerged to play a critical role in inducing inflammatory and immune responses against pathogens by regulating a crucial set of T-cell stimulatory genes. In addition to dominant effects of c-Rel on promoting Th1- and Th17mediated immune responses, this transcription factor also plays an important role by providing an initial signal for opening of the Foxp3 locus in thymic Treg cells. Although the impact of c-Rel on DC activities to induce Th2 responses has not been examined extensively, c-Reldeficient mice seem to be capable of mounting sufficient Th2 responses. Previous studies suggest that this protein is not essential for control of Th2-mediated intestinal inflammation following Trichuris muris infection. In contrast, NF- $\kappa$ B1- and NF- $\kappa$ B2-deficient mice fail to clear helminth infections [91]. Such data reflect nonoverlapping functions of individual NF- $\kappa$ B family members suggesting that targeting specific NF- $\kappa \mathrm{B}$ proteins might be a promising therapeutic approach in inflammation and infectious diseases. Especially, molecules that specifically regulate cRel-signalling pathway such as E3 ubiquitin ligase Peli1 might be of particular interests as c-Rel exhibits a unique dual capacity to regulate both tolerogenic and inflammatory responses.

\section{Abbreviations}

APC: antigen presenting cell(s)

BAFF: B-cell-activating factor

Bcl10: B-cell lymphoma 10

CREB: cAMP response element-binding protein

DC: dendritic cell(s)

GC: germinal centre

ICAM: intracellular adhesion molecule

IFN: interferon

$\mathrm{I} \kappa \mathrm{B}: \quad$ inhibitory- $\kappa \mathrm{B}$ protein

IKK: $\quad$ I $\kappa$ B kinase

ILC: innate lymphoid cell(s)

IRF: interferon regulatory factor

LT: lymphotoxin

mAb: monoclonal antibody

MALT: mucosa-associated lymphoid tissue lymphoma translocation protein 1

MAPK: mitogen-activated protein kinase

NEMO: NF- $\kappa$ B essential modifier

NFAT: nuclear factor of activated $\mathrm{T}$ cells

NF- $\kappa$ B: nuclear factor $-\kappa B$

NIK: NF- $\kappa B$ inducing kinase

NO: nitric oxide

PKC: protein kinase $\mathrm{C}$

ROR $\gamma$ t: retinoic acid-related orphan receptor $\gamma \mathrm{t}$

Ser: serine 
SRF: serum response factor

STAT: signal transducer and activator of transcription

TCR: T-cell receptor

TGF: transforming growth factor

TLR: toll-like receptor.

\section{Acknowledgments}

This work is supported by Deutsche Forschungsgemeinschaft (SFB/TR22) and Gemeinnützige Hertie-Stiftung.

\section{References}

[1] M. Pasparakis, "Regulation of tissue homeostasis by NF- $\kappa \mathrm{B}$ signalling: implications for inflammatory diseases," Nature Reviews Immunology, vol. 9, no. 11, pp. 778-788, 2009.

[2] S. Gerondakis, A. Strasser, D. Metcalf, G. Grigoriadis, J. P. Y. Scheerlinck, and R. J. Grumont, "Rel-deficient T cells exhibit defects in production of interleukin 3 and granulocytemacrophage colony-stimulating factor," Proceedings of the National Academy of Sciences of the United States of America, vol. 93, no. 8, pp. 3405-3409, 1996.

[3] T. S. Doi, T. Takahashi, O. Taguchi, T. Azuma, and Y. Obata, "NF- $\kappa$ B RelA-deficient lymphocytes: normal development of $\mathrm{T}$ cells and B cells, impaired production of IgA and IgG1 and reduced proliferative responses," Journal of Experimental Medicine, vol. 185, no. 5, pp. 953-961, 1997.

[4] H. C. Liou, Z. Jin, J. Tumang, S. Andjelic, K. A. Smith, and M. L. Liou, "c-Rel is crucial for lymphocyte proliferation but dispensable for T cell effector function," International Immunology, vol. 11, no. 3, pp. 361-371, 1999.

[5] S. Gerondakis and U. Siebenlist, "Roles of the NF-kappaB pathway in lymphocyte development and function," Cold Spring Harbor Perspectives in Biology, vol. 2, no. 5, Article ID a000182, 2010.

[6] G. Bonizzi and M. Karin, "The two NF- $\kappa$ B activation pathways and their role in innate and adaptive immunity," Trends in Immunology, vol. 25, no. 6, pp. 280-288, 2004.

[7] M. Schmidt-Supprian, G. Courtois, J. Tian et al., "Mature T cells depend on signaling through the IKK complex," Immunity, vol. 19, no. 3, pp. 377-389, 2003.

[8] S. Sanjabi, K. J. Williams, S. Saccani et al., "A c-Rel subdomain responsible for enhanced DNA-binding affinity and selective gene activation," Genes and Development, vol. 19, no. 18, pp. 2138-2151, 2005.

[9] K. Bunting, S. Rao, K. Hardy et al., "Genome-wide analysis of gene expression in T cells to identify targets of the NF- $\kappa \mathrm{B}$ transcription factor c-Rel," Journal of Immunology, vol. 178, no. 11, pp. 7097-7109, 2007.

[10] L. Wei, M. Fan, L. Xu et al., "Bioinformatic analysis reveals crel as a regulator of a subset of interferon-stimulated genes," Journal of Interferon and Cytokine Research, vol. 28, no. 9, pp. 541-551, 2008.

[11] Y. C. Lu, I. Kim, E. Lye et al., "Differential role for c-Rel and $\mathrm{C} / \mathrm{EBP} \beta / \delta$ in TLR-mediated induction of proinflammatory cytokines," Journal of Immunology, vol. 182, no. 11, pp. 72127221, 2009.

[12] S. A. De, P. De Luca, C. Moiola et al., "Identification of new $\mathrm{Rel} / \mathrm{NF} \kappa \mathrm{B}$ regulatory networks by focused genome location analysis," Cell Cycle, vol. 8, no. 13, pp. 2093-2100, 2009.
[13] S. C. Sun and S. C. Ley, "New insights into NF- $\kappa$ B regulation and function," Trends in Immunology, vol. 29, no. 10, pp. 469478, 2008.

[14] V. Heissmeyer, D. Krappmann, E. N. Hatada, and C. Scheidereit, "Shared pathways of I $\kappa \mathrm{B}$ kinase-induced SCF $\beta \operatorname{TrCP}$ mediated ubiquitination and degradation for the NF- $\kappa \mathrm{B}$ precursor p105 and $\mathrm{I} \kappa \mathrm{B} \alpha$, , Molecular and Cellular Biology, vol. 21, no. 4, pp. 1024-1035, 2001.

[15] U. Senftleben, Y. Cao, G. Xiao et al., "Activation by IKK $\alpha$ of a second, evolutionary conserved, NF- $\kappa$ B signaling pathway," Science, vol. 293, no. 5534, pp. 1495-1499, 2001.

[16] S. Vallabhapurapu and M. Karin, "Regulation and function of NF- $\kappa$ B transcription factors in the immune system," Annual Review of Immunology, vol. 27, pp. 693-733, 2009.

[17] A. Oeckinghaus, M. S. Hayden, and S. Ghosh, "Crosstalk in NF-kappaB signaling pathways," Nature Immunology, vol. 12, pp. 695-708, 2011.

[18] S. E. Murray, F. Polesso, A. M. Rowe et al., "NF-kappaBinducing kinase plays an essential $\mathrm{T}$ cell-intrinsic role in graftversus-host disease and lethal autoimmunity in mice," The Journal of Clinical Investigation, vol. 121, no. 12, pp. 47754786, 2011.

[19] C. W. Wright, J. M. Rumble, and C. S. Duckett, "CD30 activates both the canonical and alternative NF- $\kappa \mathrm{B}$ pathways in anaplastic large cell lymphoma cells," Journal of Biological Chemistry, vol. 282, no. 14, pp. 10252-10262, 2007.

[20] S. Beinke, M. P. Belich, and S. C. Ley, "The death domain of NF- $\kappa$ B1 p105 is essential for signal-induced p105 proteolysis," Journal of Biological Chemistry, vol. 277, no. 27, pp. 2416224168, 2002.

[21] S. Beinke and S. C. Ley, "Functions of NF- $\kappa$ B1 and NF- $\kappa$ B2 in immune cell biology," Biochemical Journal, vol. 382, no. 2, pp. 393-409, 2004.

[22] M. S. Hayden and S. Ghosh, "Signaling to NF- $\kappa \mathrm{B}$," Genes and Development, vol. 18, no. 18, pp. 2195-2224, 2004.

[23] P. Rao, M. S. Hayden, M. Long et al., " $\mathrm{\kappa} \kappa \mathrm{B} \beta$ acts to inhibit and activate gene expression during the inflammatory response," Nature, vol. 466, no. 7310, pp. 1115-1119, 2010.

[24] S. T. Smale, "Hierarchies of NF-kappaB target-gene regulation," Nature Immunology, vol. 12, no. 8, pp. 689-694, 2011.

[25] A. Hoffmann, A. Levchenko, M. L. Scott, and D. Baltimore, "The I $\kappa \mathrm{B}-\mathrm{NF}-\kappa \mathrm{B}$ signaling module: temporal control and selective gene activation," Science, vol. 298, no. 5596, pp. 12411245, 2002.

[26] S. L. Werner, D. Barken, and A. Hoffmann, "Stimulus specificity of gene expression programs determined by temporal control of IKK activity," Science, vol. 309, no. 5742, pp. 18571861, 2005.

[27] J. M. Clark, K. Aleksiyadis, A. Martin et al., "Inhibitor of kappa B epsilon (IkappaBepsilon) is a non-redundant regulator of cRel-dependent gene expression in murine T and B cells," Plos ONE, vol. 6, no. 9, Article ID e24504, 2011.

[28] W. F. Tam and R. Sen, "I $\kappa$ B family members function by different mechanisms," Journal of Biological Chemistry, vol. 276, no. 11, pp. 7701-7704, 2001.

[29] D. Banerjee, H. C. Liou, and R. Sen, "C-Rel-dependent priming of naive T cells by inflammatory cytokines," Immunity, vol. 23, no. 4, pp. 445-458, 2005.

[30] E. Chen, R. Hrdlickova, J. Nehyba, D. L. Longo, H. R. Bose, and C. C. H. Lit, "Degradation of proto-oncoprotein c-Rel by the ubiquitin-proteasome pathway," Journal of Biological Chemistry, vol. 273, no. 52, pp. 35201-35207, 1998.

[31] M. Chang, W. Jin, J.-H. Chang et al., "The ubiquitin ligase Pelil negatively regulates $\mathrm{T}$ cell activation and prevents 
autoimmunity," Nature Immunology, vol. 12, no. 10, pp. 1002 1009, 2011.

[32] X. O. Yang, R. Nurieva, G. J. Martinez et al., "Molecular antagonism and plasticity of regulatory and inflammatory $\mathrm{T}$ cell programs," Immunity, vol. 29, no. 1, pp. 44-56, 2008.

[33] K. M. Murphy and B. Stockinger, "Effector T cell plasticity: flexibility in the face of changing circumstances," Nature Immunology, vol. 11, no. 8, pp. 674-680, 2010.

[34] M. Veldhoen, R. J. Hocking, C. J. Atkins, R. M. Locksley, and B. Stockinger, "TGF $\beta$ in the context of an inflammatory cytokine milieu supports de novo differentiation of IL-17-producing $\mathrm{T}$ cells," Immunity, vol. 24, no. 2, pp. 179-189, 2006.

[35] B. Stockinger, M. Veldhoen, and B. Martin, "Th17 T cells: linking innate and adaptive immunity," Seminars in Immunology, vol. 19, no. 6, pp. 353-361, 2007.

[36] X. O. Yang, B. P. Pappu, R. Nurieva et al., "T Helper 17 Lineage Differentiation Is Programmed by Orphan Nuclear Receptors ROR $\alpha$ and ROR $\gamma$," Immunity, vol. 28, no. 1, pp. 29-39, 2008.

[37] Y. Chung, S. H. Chang, G. J. Martinez et al., "Critical Regulation of Early Th17 Cell Differentiation by Interleukin-1 Signaling," Immunity, vol. 30, no. 4, pp. 576-587, 2009.

[38] R. I. Nurieva, Y. Chung, D. Hwang et al., "Generation of $\mathrm{T}$ Follicular Helper Cells Is Mediated by Interleukin-21 but Independent of T Helper 1, 2, or 17 Cell Lineages," Immunity, vol. 29, no. 1, pp. 138-149, 2008.

[39] R. I. Nurieva, Y. Chung, G. J. Martinez et al., "Bcl6 mediates the development of T follicular helper cells," Science, vol. 325, no. 5943, pp. 1001-1005, 2009.

[40] E. M. Shevach, "Mechanisms of Foxp3+ T Regulatory CellMediated Suppression," Immunity, vol. 30, no. 5, pp. 636-645, 2009.

[41] S. Sakaguchi, M. Miyara, C. M. Costantino, and D. A. Hafler, "FOXP3 + regulatory T cells in the human immune system," Nature Reviews Immunology, vol. 10, no. 7, pp. 490-500, 2010.

[42] F. Kontgen, R. J. Grumont, A. Strasser et al., "Mice lacking the c-rel proto-oncogene exhibit defects in lymphocyte proliferation, humoral immunity, and interleukin-2 expression," Genes and Development, vol. 9, no. 16, pp. 1965-1977, 1995.

[43] S. Rao, S. Gerondakis, D. Woltring, and M. F. Shannon, "cRel is required for chromatin remodeling across the IL-2 gene promoter," Journal of Immunology, vol. 170, no. 7, pp. 37243731, 2003.

[44] H. C. Liou and C. Y. Hsia, "Distinctions between c-Rel and other NF- $\kappa$ B proteins in immunity and disease," BioEssays, vol. 25, no. 8, pp. 767-780, 2003.

[45] H. C. Liou and K. A. Smith, "The roles of c-rel and interleukin-2 in tolerance: a molecular explanation of selfnonself discrimination," Immunology and Cell Biology, vol. 89, pp. 27-32, 2011.

[46] J. W. Pierce, C. A. Jamieson, J. L. Ross, and R. Sen, "Activation of IL- 2 receptor $\alpha$-chain gene by individual members of the rel oncogene family in association with serum response factor," Journal of Immunology, vol. 155, no. 4, pp. 1972-1980, 1995.

[47] G. Chen, K. Hardy, K. Bunting, S. Daley, L. Ma, and M. F. Shannon, "Regulation of the IL-21 gene by the NF- $\kappa \mathrm{B}$ transcription factor c-Rel," Journal of Immunology, vol. 185, no. 4 , pp. 2350-2359, 2010.

[48] A. Vogelzang, H. M. McGuire, D. Yu, J. Sprent, C. R. Mackay, and C. King, "A fundamental role for interleukin-21 in the generation of T follicular helper cells," Immunity, vol. 29, no. 1, pp. 127-137, 2008.

[49] K. Ozaki, R. Spolski, C. G. Feng et al., "A critical role for IL-21 in regulating immunoglobulin production," Science, vol. 298, no. 5598, pp. 1630-1634, 2002.
[50] M. A. Linterman, L. Beaton, D. Yu et al., "IL-21 acts directly on B cells to regulate Bcl-6 expression and germinal center responses," Journal of Experimental Medicine, vol. 207, no. 2, pp. 353-363, 2010.

[51] D. Zotos, J. M. Coquet, Y. Zhang et al., "IL-21 regulates germinal center B cell differentiation and proliferation through a B cell-intrinsic mechanism," Journal of Experimental Medicine, vol. 207, no. 2, pp. 365-378, 2010.

[52] H. P. Kim, L. L. Korn, A. M. Gamero, and W. J. Leonard, "Calcium-dependent activation of interleukin-21 gene expression in T cells," Journal of Biological Chemistry, vol. 280, no. 26, pp. 25291-25297, 2005.

[53] M. Huber, A. Brüstle, K. Reinhard et al., "IRF4 is essential for IL-21-mediated induction, amplification, and stabilization of the Th17 phenotype," Proceedings of the National Academy of Sciences of the United States of America, vol. 105, no. 52, pp. 20846-20851, 2008.

[54] Q. Ruan, V. Kameswaran, Y. Tone et al., "Development of Foxp $3^{+}$regulatory $\mathrm{T}$ cells is driven by the c-Rel enhanceosome," Immunity, vol. 31, no. 6, pp. 932-940, 2009.

[55] M. Long, S. G. Park, I. Strickland, M. S. Hayden, and S. Ghosh, "Nuclear factor- $\kappa \mathrm{B}$ modulates regulatory $\mathrm{T}$ cell development by directly regulating expression of Foxp3 transcription factor," Immunity, vol. 31, no. 6, pp. 921-931, 2009.

[56] C. S. Hsieh, "Kickstarting Foxp3 with c-Rel," Immunity, vol. 31, no. 6, pp. 852-853, 2009.

[57] K. B. Vang, J. Yang, A. J. Pagán et al., "Cutting edge: CD28 and c-Rel-dependent pathways initiate regulatory T cell development," Journal of Immunology, vol. 184, no. 8, pp. 4074-4077, 2010.

[58] I. Isomura, S. Palmer, R. J. Grumont et al., "c-Rel is required for the development of thymic Foxp $3{ }^{+} \mathrm{CD} 4$ regulatory T cells," Journal of Experimental Medicine, vol. 206, no. 13, pp. 30013014, 2009.

[59] Y. Zheng, S. Josefowicz, A. Chaudhry, X. P. Peng, K. Forbush, and A. Y. Rudensky, "Role of conserved non-coding DNA elements in the Foxp3 gene in regulatory T-cell fate," Nature, vol. 463, no. 7282, pp. 808-812, 2010.

[60] A. Visekruna, M. Huber, A. Hellhund et al., "c-Rel is crucial for the induction of Foxp $3^{+}$regulatory $\mathrm{CD}^{+} \mathrm{T}$ cells but not $\mathrm{T}_{H} 17$ cells," European Journal of Immunology, vol. 40, no. 3, pp. 671-676, 2010.

[61] S. Gupta, S. Manicassamy, C. Vasu, A. Kumar, W. Shang, and Z. Sun, "Differential requirement of PKC- $\theta$ in the development and function of natural regulatory $\mathrm{T}$ cells," Molecular Immunology, vol. 46, no. 2, pp. 213-224, 2008.

[62] L. L. Molinero, J. Yang, T. Gajewski, C. Abraham, M. A. Farrar, and M. L. Alegre, "CARMA1 controls an early checkpoint in the thymic development of FoxP $3^{+}$regulatory T cells," Journal of Immunology, vol. 182, no. 11, pp. 6736-6743, 2009.

[63] M. J. Barnes, P. Krebs, N. Harris et al., "Commitment to the regulatory t cell lineage requires CARMA1 in the thymus but not in the periphery," Plos Biology, vol. 7, no. 3, Article ID e1000051, 2009.

[64] S. D. Saibil, R. G. Jones, E. K. Deenick et al., "CD4 ${ }^{+}$and $\mathrm{CD} 8^{+}$ $\mathrm{T}$ cell survival is regulated differentially by protein kinase Ctheta c-Rel, and protein kinase B," Journal of Immunology, vol. 178, no. 5, pp. 2932-2939, 2007.

[65] L. Harling-McNabb, G. Deliyannis, D. C. Jackson, S. Gerondakis, G. Grigoriadis, and L. E. Brown, "Mice lacking the transcription factor subunit Rel can clear an influenza infection and have functional anti-viral cytotoxic $\mathrm{T}$ cells but do not develop an optimal antibody response," International Immunology, vol. 11, no. 9, pp. 1431-1439, 1999. 
[66] S. Sanjabi, A. Hoffmann, H. C. Liou, D. Baltimore, and S. T. Smale, "Selective requirement for c-Rel during IL-12 P40 gene induction macrophages," Proceedings of the National Academy of Sciences of the United States of America, vol. 97, no. 23, pp. 12705-12710, 2000.

[67] R. Grumont, H. Hochrein, M. O’Keeffe et al., "c-Rel regulates interleukin 12 p70 expression in $\mathrm{CD}^{+}$dendritic cells by specifically inducing p35 gene transcription," Journal of Experimental Medicine, vol. 194, no. 8, pp. 1021-1031, 2001.

[68] J. I. Kollet and T. M. Petro, "IRF-1 and NF- $\kappa$ B p50/cRel bind to distinct regions of the proximal murine IL-12 p35 promoter during costimulation with IFN- $\gamma$ and LPS," Molecular Immunology, vol. 43, no. 6, pp. 623-633, 2006.

[69] S. Mise-Omata, E. Kuroda, J. Niikura, U. Yamashita, Y. Obata, and T. S. Doi, "A proximal $\kappa$ B site in the IL-23 p19 promoter is responsible for RelA- and c-Rel-dependent transcription," Journal of Immunology, vol. 179, no. 10, pp. 6596-6603, 2007.

[70] R. J. Carmody, Q. Ruan, H. C. Liou, and Y. H. Chen, "Essential roles of c-Rel in TLR-induced IL-23 p19 gene expression in dendritic cells," Journal of Immunology, vol. 178, no. 1, pp. 186-191, 2007.

[71] D. J. Boffa, B. Feng, V. Sharma et al., "Selective loss of cRel compromises dendritic cell activation of T lymphocytes," Cellular Immunology, vol. 222, no. 2, pp. 105-115, 2003.

[72] G. Grigoriadis, Y. Zhan, R. J. Grumont et al., “The Rel subunit of NF- $\kappa$ B-like transcription factors is a positive and negative regulator of macrophage gene expression: distinct roles for Rel in different macrophage populations," The EMBO Journal, vol. 15, no. 24, pp. 7099-7107, 1996.

[73] A. Debus, J. Gläsner, M. Röllinghoff, and A. Gessner, "High levels of susceptibility and T helper 2 response in MyD88deficient mice infected with leishmania major are interleukin4 dependent," Infection and Immunity, vol. 71, no. 12, pp. 7215-7218, 2003.

[74] K. Reinhard, M. Huber, C. Wostl et al., "c-Rel promotes type 1 and type 17 immune responses during Leishmania major infection," European Journal of Immunology, vol. 41, no. 5, pp. 1388-1398, 2011.

[75] N. J. Mason, H. C. Liou, and C. A. Hunter, “T cell-intrinsic expression of c-Rel regulates Th1 cell responses essential for resistance to toxoplasma gondii," Journal of Immunology, vol. 172, no. 6, pp. 3704-3711, 2004.

[76] N. Mason, J. Aliberti, J. C. Caamano, H. C. Liou, and C. A. Hunter, "Cutting edge: identification of c-Rel-dependent and -independent pathways of IL-12 production during infectious and inflammatory stimuli," Journal of Immunology, vol. 168, no. 6, pp. 2590-2594, 2002.

[77] B. A. Hilliard, N. Mason, L. Xu et al., "Critical roles of c-Rel in autoimmune inflammation and helper T cell differentiation," Journal of Clinical Investigation, vol. 110, no. 6, pp. 843-850, 2002.

[78] G. Chen, K. Hardy, E. Pagler et al., "The NF- $\kappa$ B transcription factor c-Rel is required for Th17 effector cell development in experimental autoimmune encephalomyelitis," Journal of Immunology, vol. 187, no. 9, pp. 4483-4491, 2011.

[79] Y. Wang, B. H. Rickman, T. Poutahidis et al., "C-Rel is essential for the development of innate and T cell-induced colitis," Journal of Immunology, vol. 180, no. 12, pp. 8118-8125, 2008.

[80] A. Visekruna, T. Joeris, D. Seidel et al., "Proteasome-mediated degradation of $\mathrm{I} \kappa \mathrm{B} \alpha$ and processing of p105 in Crohn disease and ulcerative colitis," Journal of Clinical Investigation, vol. 116, no. 12, pp. 3195-3203, 2006.
[81] K. J. Maloy and F. Powrie, "Intestinal homeostasis and its breakdown in inflammatory bowel disease," Nature, vol. 474, pp. 298-306, 2011.

[82] R. H. Duerr, K. D. Taylor, S. R. Brant et al., "A genome-wide association study identifies IL23R as an inflammatory bowel disease gene," Science, vol. 314, no. 5804, pp. 1461-1463, 2006.

[83] S. Hue, P. Ahern, S. Buonocore et al., "Interleukin-23 drives innate and T cell-mediated intestinal inflammation," Journal of Experimental Medicine, vol. 203, no. 11, pp. 2473-2483, 2006.

[84] P. P. Ahern, A. Izcue, K. J. Maloy, and F. Powrie, "The interleukin-23 axis in intestinal inflammation," Immunological Reviews, vol. 226, no. 1, pp. 147-159, 2008.

[85] P. P. Ahern, C. Schiering, S. Buonocore et al., "Interleukin23 drives intestinal inflammation through direct activity on T cells," Immunity, vol. 33, no. 2, pp. 279-288, 2010.

[86] Q. Ruan, V. Kameswaran, Y. Zhang et al., "The Th17 immune response is controlled by the Rel-ROR $\gamma$-ROR $\gamma \mathrm{T}$ transcriptional axis," The Journal of Experimental Medicine, vol. 208, no. 11, pp. 2321-2333, 2011.

[87] N. Schmidt, E. Gonzalez, A. Visekruna et al., "Targeting the proteasome: partial inhibition of the proteasome by bortezomib or deletion of the immunosubunit LMP7 attenuates experimental colitis," Gut, vol. 59, no. 7, pp. 896-906, 2010.

[88] M. Basler, M. Dajee, C. Moll, M. Groettrup, and C. J. Kirk, "Prevention of experimental colitis by a selective inhibitor of the immunoproteasome," Journal of Immunology, vol. 185, no. 1, pp. 634-641, 2010.

[89] S. Buonocore, P. P. Ahern, H. H. Uhlig et al., "Innate lymphoid cells drive interleukin-23-dependent innate intestinal pathology," Nature, vol. 464, no. 7293, pp. 1371-1375, 2010.

[90] A. Geremia, C. V. Arancibia-Cárcamo, M. P. Fleming et al., "IL-23-responsive innate lymphoid cells are increased in inflammatory bowel disease," Journal of Experimental Medicine, vol. 208, no. 6, pp. 1127-1133, 2011.

[91] D. Artis, S. Shapira, N. Mason et al., "Differential requirement for NF- $\kappa$ B family members in control of helminth infection and intestinal inflammation," Journal of Immunology, vol. 169, no. 8, pp. 4481-4487, 2002. 


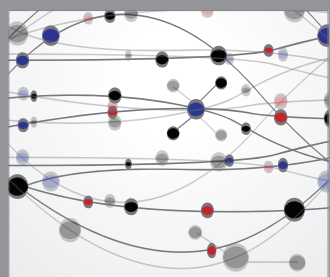

The Scientific World Journal
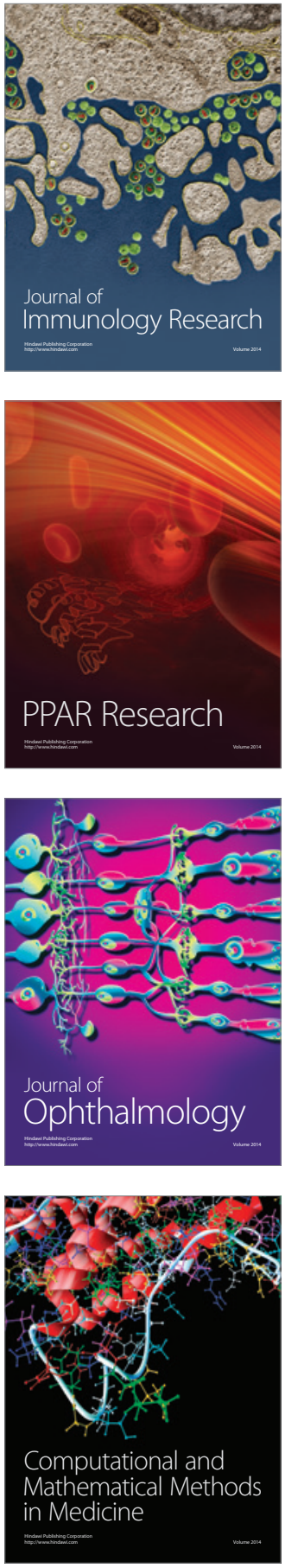

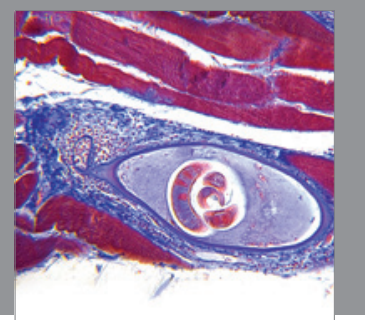

Gastroenterology

Research and Practice
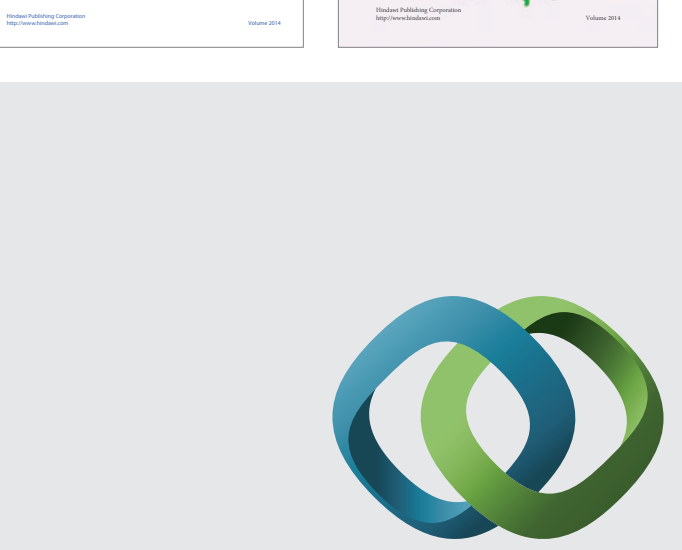

\section{Hindawi}

Submit your manuscripts at

http://www.hindawi.com
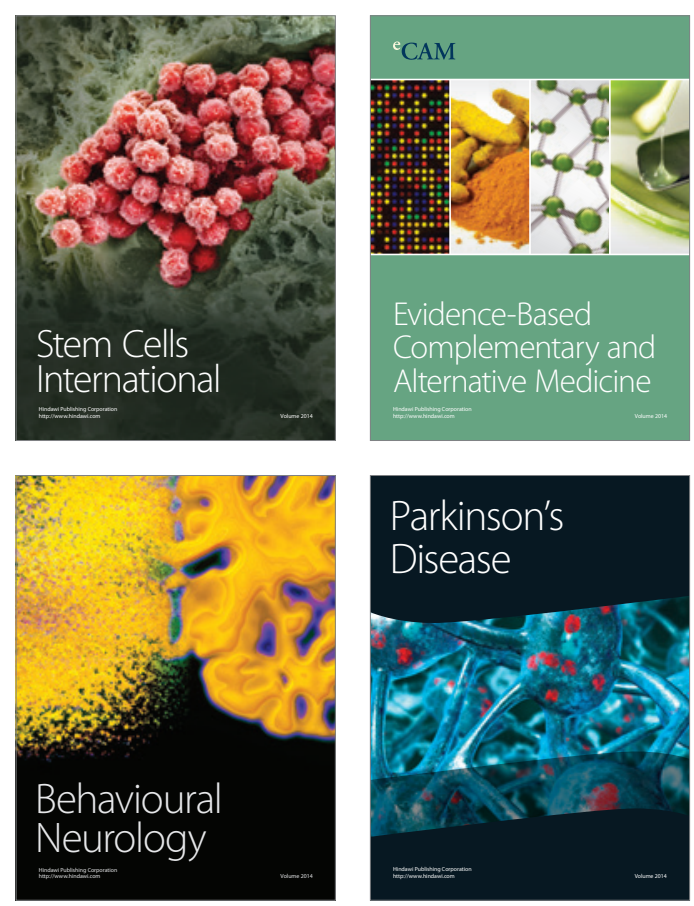

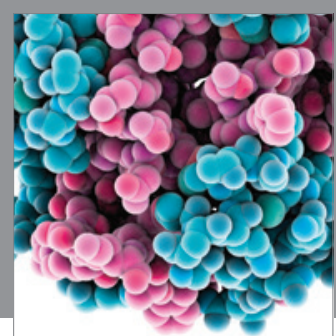

Journal of
Diabetes Research

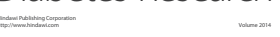

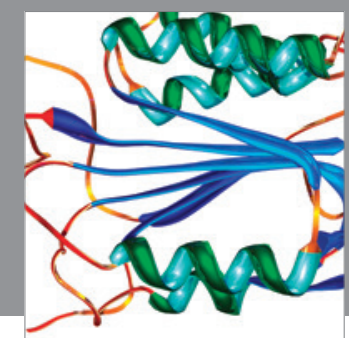

Disease Markers
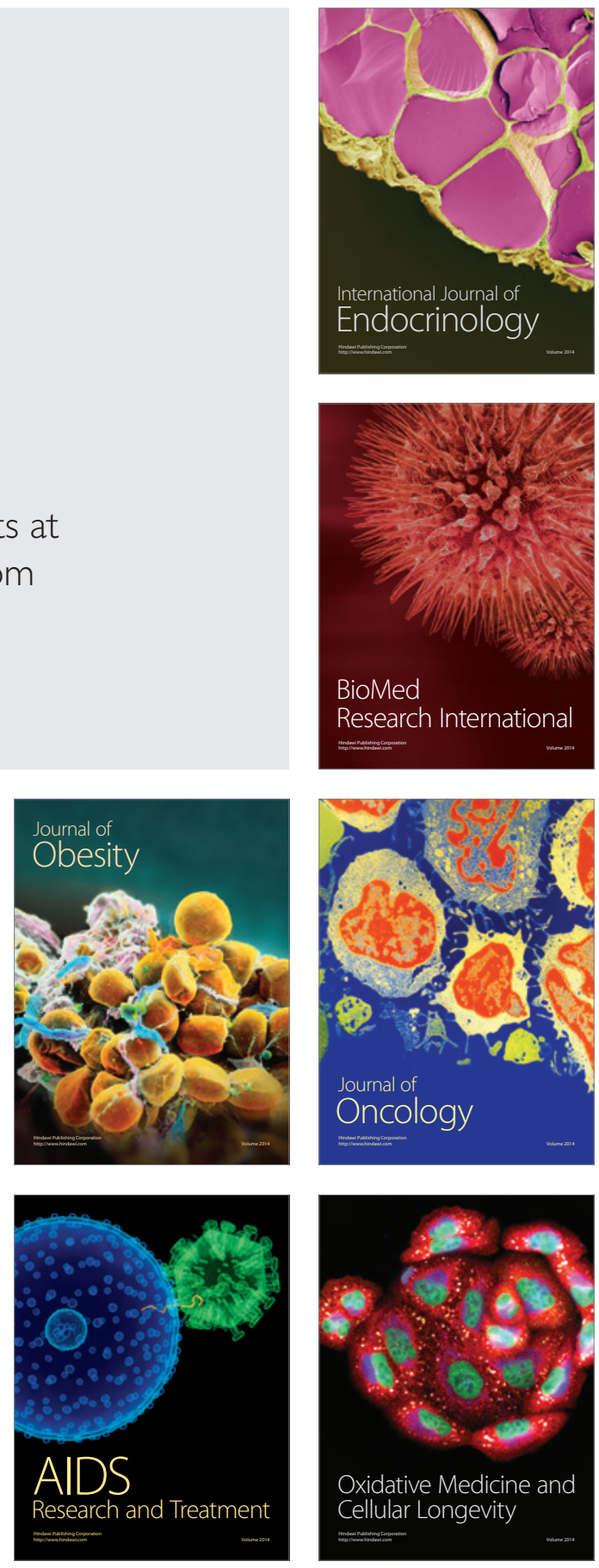